\title{
Highly bioactive silver and silver/titania composite films grown by chemical vapour deposition
}

\author{
L.A.Brook, P. Evans, H.A. Foster, M.E. Pemble ${ }^{\text {b }}$ A. Steele, D. W. Sheel* , H.M.Yates \\ Institute for Materials Research, Salford University, Manchester, M5 4WT \\ ${ }^{\mathrm{b}}$ Current address: Tyndall National Institute, University College Cork, Lee Maltings, \\ Prospect Row, Cork, Ireland. \\ *Email corresponding au thor: D.W.Sheel@salford.ac.uk
}

\begin{abstract}
This paper describes how photocatalytically active films of $\mathrm{TiO}_{2}$, grown by thermal CVD, may be functionally and structurally modified by deposition of nanostructured silver via a novel flame assisted CVD process. The resulting composite films are shown to be highly durable, highly photocatalytically active and are also shown to possess strong antibacterial behaviour.

The deposition control, arising from the described approach, offers the potential to control the film nanostructure, which is proposed to be crucial in determining the photo and bio-activity of the combined film structure, and the transparency of the composite films.

Furthermore, we show that the resultant films also exhibit "self regeneration" capability, in that they both kill bacteria present on the film surface and then photodegrade the residues. Such a dual action significantly reducing the problems of surface deactivation due to build up of contamination.

These properties are especially significant when combined with the well-known durability of CVD deposited thin films, offering new opportunities for enhanced application in areas where bio-active surface functionality is sought.
\end{abstract}




\section{Introduction}

In recent years $\mathrm{TiO}_{2}$ has been widely investigated for its interesting photoactive properties, which, for example, can lead to the decomposition of organics into harmless products under UV light irradiation ${ }^{[1]}$. The extent of the photo-activity depends on a wide range of properties including morphology, crystallinity and surface area.

The use of $\mathrm{TiO}_{2}$ as a biocide was first demonstrated by Matsunaga et al. (1985) ${ }^{[2]}$. Subsequently, there have been a number of reports of disinfection of bacteria, viruses and other micro-organisms. Most of this early work ${ }^{[3]}$ used suspensions of $\mathrm{TiO}_{2}$ and planktonic organisms. More recently, research had examined the biocidal activity of organisms on thin films of $\mathrm{TiO}_{2}$ anchored to solid surfaces ${ }^{[4,5,6,7]}$. Maness et al. have suggested that the mechanism by which silver is able to kill bacteria involves the disruption of the cell membrane following peroxidation of the membrane lipids by active oxygen species ${ }^{[3]}$. This is supported by the work of Sunada ${ }^{[8]}$ et al. who studied killing of Escherichia coli on thin films and showed that firstly, the outer membrane was damaged followed by the cytoplamic membrane and that these processes then allowed the complete degradation of the cells. Amézaga-Madrid ${ }^{[9]}$ studied the inactivation of Pseudomonas aeruginosa and showed cell damage consistent with membrane and cell-wall damage.

Bulk Ag has been long used for coatings many items including mirrors (for reflectance properties) and electrical contacts, as it is the most conductive of all metals. There is particular interest in nano-particulate Ag due to its ability to act as both an electron sink and as redox catalyst. The antimicrobial properties of silver were well known to the ancient Egyptians and Greeks, for example Hippocrates mentions silver as a treatment for ulcers ${ }^{[10]}$. Since then silver has been widely used as an antimicrobial agent in applications such as wound dressings and as surface coatings for e.g. catheters ${ }^{[11,12]}$. Silver has also been incorporated into bioglass ${ }^{[13]}$. Silver ions $\left(\mathrm{Ag}^{+}\right)$interact strongly with electron donors and the antimicrobial activity of Ag primarily involves interactions with sulphydryl groups in proteins ${ }^{[14,15,16]}$. Silver also reacts with other cellular components such as nucleic acids ${ }^{[17]}$. Silver has been shown to inhibit energy production by inhibition of the respiratory chain of 
Escherichia coli ${ }^{[18]}$. Indirect toxicity may also arise from salt formation with silver ions that results in a chloride or anion limitation within the cell. Nanocrystalline silver ${ }^{[19]}$ also releases $\mathrm{Ag}^{0}$ and has been shown to rapidly kill bacteria and fungi ${ }^{[20]}$. Although $\mathrm{Ag}^{+}$is rapidly inactivated by interaction with organic matter, $\mathrm{Ag}^{0}$ is much more stable ${ }^{[21]}$.

The combination of $\mathrm{Ag}$ and $\mathrm{TiO}_{2}$ for catalysis has been much studied for mainly solgel produced materials ${ }^{[22,23,24]}$ with some colloid production of mixed ${ }^{[25]}$ and coreshell composite clusters ${ }^{[26]}$. Most of these papers conclude that $\mathrm{Ag}$ is capable, under the correct conditions, of improving $\mathrm{TiO}_{2}$ photoactivity. The addition of $\mathrm{Ag}$ promotes the charge separation of the electron-hole pairs from $\mathrm{TiO}_{2}$ after photon absorption by acting as an electron sink. Also the plasmon resonance in metallic Ag nanoparticles is considered to locally enhance the electric field facilitating electron-hole production $^{[27]}$. While most relate this improvement to electronic effects, it has been pointed out that the addition of $\mathrm{Ag}$ can modify the grain sizes of the $\mathrm{TiO}_{2}$, so increasing the surface area and hence also the photoactivity ${ }^{[23]}$.

Previous studies have also shown that addition of silver can enhance photocatalytic activity of $\mathrm{TiO}_{2}$. For example Kato ${ }^{[28]}$ et al. showed that photo-deposition of $\mathrm{Ag}$ on a $\mathrm{TiO}_{2}$ film enhanced photocatalytic degradation of gaseous sulphur compounds and suggested that $\mathrm{Ag}$ acted as a co-catalyst. Sokmen ${ }^{[29]}$ et al. showed that addition of $\mathrm{AgNO}_{3}$ to anatase (form of $\mathrm{TiO}_{2}$ ) enhanced the photocatalytic activity and enhanced the killing of Escherichia coli in suspension. Ag enhanced the biocidal activity of photo-deposited silver on glazed sanitary ware ${ }^{[30]}$. The biocidal activity depended on thickness of the $\mathrm{TiO}_{2}$ film, the amount of $\mathrm{Ag}$ and calcination temperature. Silver- $\mathrm{TiO}_{2}$ combinations have also been used in surgical face masks ${ }^{[31]}$.

In this paper, we report on the production of layered $\mathrm{Ag} / \mathrm{TiO}_{2}$ thin films by atmospheric pressure CVD, using conventional thermal CVD film and a new flame assisted based CVD process to directly deposit Ag from an aqueous solution of $\mathrm{AgNO}_{3}$. No previous work exists in which atmospheric pressure CVD methods have been shown to be capable of growing the layered films described here. This is mainly due to the problems inherent in producing thin Ag films by CVD. This then highlights the fact that the method described in this present work is a major advance in Ag CVD technology. 
Atmospheric pressure CVD growth requires precursors with moderately high vapour pressures. For deposition based on less volatile precursors, vacuum conditions are often used, and this is normally the case for silver CVD ${ }^{[32]}$. Direct liquid injection MOCVD (DLI-MOCVD) reduces the need for very volatile reactants so widening the possibilities of using relatively low volatility precursors such as Ag carboxylates ${ }^{[33]}$. The need to use organic solvents constrains the commercial uses of this method. Edwards et al. reported ${ }^{[34]}$ deposition of silver films by aerosol assisted CVD (AACVD) using phosphine adducts of beta-diketonates. AACVD is a variant of DLIMOCVD which involves producing a very fine mist of a liquid precursor (or a solution of the precursor). However the growth rates reported were a maximum 0.9 $\mathrm{nm} \min ^{-1}$ while the crystallinity of the resulting films was highly variable.

Our alternative approach, which we describe in this present paper, uses an aqueous solution of an inorganic $\mathrm{Ag}$ salt $\left(\mathrm{AgNO}_{3}\right)$ with an aerosol to produce films of highly crystalline nano-particulate $\mathrm{Ag}$, with growth rates of $50 \mathrm{~nm} \mathrm{~min}{ }^{-1}$ easily obtainable. This approach is based on the method of flame assisted CVD (FACVD)

FACVD is a low-cost, relatively simple atmospheric pressure CVD technique that is compatible with small volume, batch, and high volume continuous coating processes. A flame is used to provide the energy required to crack the precursor species into fragments and subsequently forms the film upon the substrate. Use of this method with low hazard aqueous solutions of simple metal salts can yield thin films, which represents a major advantage in terms of precursor cost and environmental impact compared to alternative CVD methods.

Although powders can produce excellent photocatalytic materials, for many practical applications thin films are more appropriate. Of all the methods used (spin coatings, sol-gel, spray etc) CVD has strong attractions in that it can be the most compatible approach to industrial scale production methods. Furthermore, CVD can produce strongly adhesive, robust, transparent thin films. These film properties contrast with those produced by the sol- gel approach that typically results in thicker films, which are less mechanically robust and often require post-coating annealing. 
In this paper we show that the resultant films also exhibit a degree of "self cleaning" capability, thus both killing bacteria and photo-degrading the residues, and thereby significantly reducing the problems of surface deactivation due to build up of contamination.

\section{Experimental}

2.1 Growth: All films were grown on pre-coated (CVD) silica coated barrier glass substrates. The barrier was a $(60 \mathrm{~nm})$, amorphous film of $\mathrm{SiO}_{2}$ designed to prevent diffusion of impurity ions within the float glass. These would all cause a reduction in the quality and photo-activity of the films. All $\mathrm{TiO}_{2}$ films were grown using an atmospheric pressure CVD coater described previously ${ }^{[35]}$. The precursors used were either titanium tetrachloride $\left(4.9 \times 10^{-4} \mathrm{~mol} \mathrm{~min}^{-1}\right)$ and ethyl acetate $\left(3.65 \times 10^{-3} \mathrm{~mol}\right.$ $\left.\mathrm{min}^{-1}\right)$ or titanium tetraisopropoxide $\left(7.79 \times 10^{-4} \mathrm{~mol} \mathrm{~min}^{-1}\right)$ (TTIP) (all from Aldrich), which are transported through the reactor by a carrier gas of nitrogen. The substrate temperature was $650{ }^{\circ} \mathrm{C}$ for $\mathrm{TiCl}_{4}$ and $500{ }^{\circ} \mathrm{C}$ for TTIP.

The Ag films were grown using an atmospheric pressure combustion coater with a propane/oxygen flame, described in detail previously ${ }^{[36]}$. The substrate temperature was set at $300{ }^{\circ} \mathrm{C}$. An aqueous solution of $0.5 \mathrm{M} \mathrm{AgNO}_{3}$ was nebulised, into a carrier of $\mathrm{N}_{2}$, through the flame and onto the substrate. From this description, the reader will appreciate the simplicity, elegance and potential for exploitation of this new process.

2.2 Characterisation: Standard techniques of X-ray diffraction (Siemens D5000), micro-Raman $514.5 \mathrm{~nm}$ Ar line (Renishaw 1000), uv/visible spectroscopy (Hewlett Packard HP895A) and SEM (Philips XL30) were used to characterise the samples. Film thickness was estimated by relating the reflected colour to a calibrated chart for thickness versus refractive index. X-ray photoelectron Spectroscopy, XPS, (Kratos AXIS Ultra) with an $\mathrm{Al}$ (monochromated) $\mathrm{K}_{\alpha}$ radiation source was used to check the surface characteristics of the films. It was necessary to use a charge neutraliser as all the samples were insulating, due mainly to the deposition on glass. This tends to shift the peak positions up to $2 \mathrm{eV}$ so the measurements are referenced to the residual $\mathrm{C} 1 \mathrm{~s}$ signal at $285 \mathrm{eV}$. Curve fitting used CASA XP software using a mixture of GaussianLorentzian functions to deconvolute spectra. 
To test the functional behaviour of the samples, both photoactivity and bioactivity were tested.

2.21 Photocatalytic behaviour: This was measured under uv $(365 \mathrm{~nm})$. The degradation of stearic acid was followed by FTIR (Bruker, Vector 22). Stearic acid ( $100 \mu \mathrm{l}$ of $10 \mathrm{mmol}$ in methanol) was spun coated on to the sample. After drying in an oven at $55{ }^{\circ} \mathrm{C}$ the sample was exposed to uv light with an intensity of $3 \mathrm{~mW} / \mathrm{cm}^{2}$. The activity of the film was defined in $\mathrm{cm}^{-1} \mathrm{~min}^{-1}$, which indicated the rate of reduction in selected stearic acid peaks in the IR region. The technique used ${ }^{[37]}$ was developed from work described previously ${ }^{[38,39,40]}$.

2.22 Bioactivity testing: The test used was a modification of the standard test described by BS EN 13697:2001. Sample cleaning was performed by ultra-sonication for $40 \mathrm{~min}$ in $40 \mathrm{ml}$ of $100 \%$ methanol in an ultrasonic bath (Beckton-Dickinson, NJ, USA). Samples were removed aseptically and placed in a UVA transparent disposable plastic Petri dish, film side uppermost. The coated samples were then pre-irradiated by placing them under a $40 \mathrm{~W}$ UVA bulb with a $2.24 \mathrm{~mW} \mathrm{~cm}^{2}$ output for $24 \mathrm{~h}$.

Escherichia coli ATCC 10536 was sub-cultured into Nutrient Broth (Oxoid, Basingstoke, UK and inoculated onto Cryobank beads (Mast Diagnostics, Liverpool, UK) and the plate stored at $-70^{\circ} \mathrm{C}$. Beads were subcultured onto nutrient agar (Oxoid) and incubated at $37^{\circ} \mathrm{C}$ for $24 \mathrm{~h}$ and stored at $5^{\circ} \mathrm{C}$. A $50 \mu 1$ loopful was inoculated in to $20 \mathrm{ml}$ Iso-sensitest broth (Oxoid) and incubated for $24 \mathrm{~h}$ at $37^{\circ} \mathrm{C}$. Cultures were centrifuged at $5000 \mathrm{xg}$ for $10 \mathrm{~min}$ in a bench centrifuge and the cells were washed in de-ionised water three times by centrifugation and re-suspension. Cultures were resuspended in water and adjusted to OD 0.5 at $600 \mathrm{~nm}$ in a spectrophotometer (Camspec, M330, Cambridge, UK) to give approximately $2 \times 10^{8}$ colony forming units (cfu) $\mathrm{ml}^{-1}$ which were inoculated on to each test sample and spread out using the edge of a flame sterilized microscope cover slip.

The prepared samples were then UV activated. Four samples were exposed to three 15w UVA lamps at $2.29 \mathrm{mw} \mathrm{cm}^{2}$. At time zero, a sample was removed immediately and the remaining samples removed at regular intervals. Four samples exposed to UVA but covered with a polylaminar UVA protection film (Anglia Window Films UK) to block UVA but not infra-red, acted as controls. 
The samples were then immersed in $40 \mathrm{ml}$ of sterile de-ionised water and vortexed for 60 seconds to re-suspend the bacteria. A viability count was performed by serial dilution and plating on to nutrient agar in triplicate and incubation at $37^{\circ} \mathrm{C}$ for $48 \mathrm{~h}$. Each experiment was performed in triplicate.

\section{Results and discussion}

In order to understand the influence of the various layer structures, four types of film were produced and characterised. That of just $\mathrm{Ag}, \mathrm{TiO}_{2} / \mathrm{Ag}$ (deposited sequentially to form layers of $\mathrm{Ag}$ both over and under $\mathrm{TiO}_{2}$ ) and $\mathrm{TiO}_{2}$ for reference. The two multilayered structures were deposited, so that the effect of Ag either above or below the $\mathrm{TiO}_{2}$ layer could be assessed. The Ag films were produced with a range of thickness $(60-90 \mathrm{~nm})$, by increasing the number of passes of the moving substrate under the flame (see ref. 37 for a full description of the FACVD system). The number of passes being approximately linearly related to the thickness.

\subsection{Visual properties}

The $\mathrm{TiO}_{2}$ films (single and combined) were all transparent, showing interference fringes of varying colour depending on their thickness $(40-120 \mathrm{~nm})$. All these films were very strongly adhered to the substrate. Visually all the Ag films were reflective, with a pale pink tinge, which darkened to purple for thicker coatings, and eventually developed a silver appearance. The multilayered films were again reflective, those with $\mathrm{TiO}_{2}$ grown over the Ag exhibiting accentuation of the reflected colour relating to the $\mathrm{TiO}_{2}$ thickness. There was an increased hardness of $\mathrm{TiO}_{2} / \mathrm{Ag}$ over $\mathrm{Ag}$, which was relatively soft.

\subsection{Crystallinity}

\subsubsection{XRD}

All Ag films were crystalline showing metallic cubic Ag only (JCPDS 04-0783).

Those films of $\mathrm{Ag} / \mathrm{TiO}_{2}$ showed no mixed species-only those of $\mathrm{Ag}$ and $\mathrm{TiO}_{2}$. $\mathrm{TiO}_{2}$ grown from $\mathrm{TiCl}_{4}$ and ethyl acetate as the bottom layer (directly onto the glass substrate) was, as expected anatase only. However, when these precursors were used to grow $\mathrm{TiO}_{2}$ over $\mathrm{Ag}$ the film showed the presence of some rutile as well as anatase. Calculations ${ }^{[41]}$ using the $\mathrm{TiO}_{2}(101)$ anatase diffraction peak at $25^{\circ}$ and that of the 
rutile (110) peak at $27^{\circ}$ give a ca. $58 \mathrm{wt} \%$ rutile for a sample grown on a thick $\mathrm{Ag}$ layer (30 passes) and $33 \mathrm{wt} \%$ for a sample grown on a thin Ag layer (2 passes). In this quantification of rutile /anatase by peak height, we assume no influence of preferred orientation effects. The difference in amounts of rutile between the two samples relating to the surface coverage of the Ag. The formation of rutile was surprising as the conditions used were those which when used directly on glass, form only anatase

When the overlayer TiO2 was grown using TTIP, only anatase was seen. Formation of only anatase with TTIP and a mixture of rutile and anatase with $\mathrm{TiCl}_{4}$ have been seen previously by the authors when growing $\mathrm{TiO}_{2}$ on another conducting material ${ }^{[42]}$ $\left(\mathrm{SnO}_{2}\right)$ and on steel ${ }^{[43]}$. This may partly relate to the effect of a different substrate as previously noted ${ }^{[44]}$, as in one case the $\mathrm{TiO}_{2}$ is growing on amorphous $\mathrm{SiO}_{2}$ and on crystalline Ag in the other. However this does not explain why on the same substrate use of different precursors promote either rutile or anatase, and there is clearly a strong CVD chemical structure-directing influence, which we will shortly report on separately ${ }^{[44]}$.

Use of Scherrers formula ${ }^{[45]}$ allows the calculation of crystallite size. The calculation is ideally for a powder not a thin film, so will contain line width broadening from strain as well as crystallite size. Despite these reservations the values obtained will give an idea of the changes occurring.

Considering one of the thicker $\mathrm{Ag}$ samples there was an apparent increase in $\mathrm{Ag}$ crystallite size from $21 \mathrm{~nm}$ to $59 \mathrm{~nm}$ on addition of the $\mathrm{TiO}_{2}$ layer. In this case this most likely arises due to the high $\mathrm{TiO}_{2}$ growth temperature $\left(650{ }^{\circ} \mathrm{C}\right)$, leading to annealing and growth of the Ag crystallites. As an independent check, an Ag sample was heated $\left(650{ }^{\circ} \mathrm{C}, 10^{\circ} \mathrm{min}^{-1}\right)$ without the addition of more Ag. Although some vaporisation of the silver film appeared to have occurred, it was possible to calculate that the crystallite size still increased significantly $(21 \mathrm{~nm}$ to $37 \mathrm{~nm})$ on heating under these conditions.

Similar calculations, on the samples consisting of $\mathrm{Ag}$ layers covered by overlayers of $\mathrm{TiO}_{2}$, suggest crystallite size values of $33 \mathrm{~nm}$ and $51 \mathrm{~nm}$ for anatase and rutile respectively. The anatase value was similar to that calculated from other $\mathrm{TiO}_{2}$ films (of similar thickness) grown under identical conditions (average $30 \mathrm{~nm}$ ). There was no obvious change in crystallite size in $\mathrm{TiO}_{2}$ when it is the lower layer, as expected 
since relatively low temperatures $\left(300{ }^{\circ} \mathrm{C}\right)$ were used to deposit the Ag. Similarly, the crystallite size for $\mathrm{Ag}$ growth either on $\mathrm{TiO}_{2}$ or directly on the barrier glass appeared to be equivalent in all cases, indicating that the CCVD deposition process was controlling this property.

In contrast to the case for growth of the $\mathrm{TiO} 2$ layer using $\mathrm{TiCl} 4$ and ethyl acetate, growth using TTIP, over a thin layer of Ag produced no changes in the Ag crystallite size. This is attributed to the lower growth temperature $\left(500{ }^{\circ} \mathrm{C}\right)$ which was probably not high enough to alter the Ag crystallite size. The anatase crystallite size was $30 \mathrm{~nm}$, which is in line with that produced previously with $\mathrm{TiCl}_{4}$ and ethyl acetate.

\subsubsection{Raman}

Titania and titania underlayer samples grown using $\mathrm{TiCl}_{4}$ and Ethyl Acetate confirmed the presence of anatase $\left(398,515,636 \mathrm{~cm}^{-1}\right)$. For $\mathrm{TiO}_{2}$ over silver, a mixture of anatase and rutile was present (Fig. 1). For those samples grown using TTIP, only anatase was seen. These values can be assigned from the literature ${ }^{[46]}$ as the $B_{1 g}, B_{1 g}+A_{2 g}$ and $E_{g}$ modes. The rutile could only be seen as either a small peak $\left(449 \mathrm{~cm}^{-1}\right)$ or as a shoulder $\left(612 \mathrm{~cm}^{-1}\right)$ to the anatase peak.

There was an additional signal at $972 \mathrm{~cm}^{-1}$ which was the only signal seen for the reference thick Ag sample. This is tentatively assigned to a plasmon resonance, which is generally defined as a coupled oscillation of conductance electrons when interacting with an external electromagnetic wave of specific wavelength. The position of the plasmon relates to the size (shape or distribution) of the $\mathrm{Ag}$ particles ${ }^{[47}$, 48].

\subsection{Chemic al Composition}

XPS of all the samples containing Ag confirmed this to be metallic Ag with the $3 \mathrm{~d}_{5 / 2}$ peak appearing at $368.7 \mathrm{eV}$ and only an $\mathrm{O} 1 \mathrm{~s}$ signal at $533 \mathrm{eV}$ relating to absorbed water and no signal for an oxide $(528.2-531 \mathrm{eV})^{[49]}$. XPS of all the samples (Ag, $\mathrm{TiO}_{2}, \mathrm{TiO}_{2} / \mathrm{Ag}, \mathrm{Ag} / \mathrm{TiO}_{2}$ ) showed no major impurities in the wide scan, save the expected presence of $\mathrm{C}$ (standard calibration reference) and small amounts of $\mathrm{Cl}$ in the case of $\mathrm{TiO}_{2}$ grown from $\mathrm{TiCl}_{4}$ and ethyl acetate. Of major importance was the fact that both multilayer samples show signals from both $\mathrm{TiO}_{2}$ and $\mathrm{Ag}$. As XPS only samples about $5 \mathrm{~nm}$ of the surface, this established that the surface consists of both $\mathrm{Ag}$ and $\mathrm{TiO}_{2}$. 
A high resolution scan of the Ag 3d region (Figure 2a) for the reference Ag film (30 passes) showed a $3 \mathrm{~d}_{5 / 2}$ peak at $368.7 \mathrm{eV}$ and a $3 \mathrm{~d}_{3 / 2}$ peak at $374.7 \mathrm{eV}$, which were both shifted to lower binding energies when $\mathrm{TiO}_{2}$ was grown on the same $\mathrm{Ag}$ film $\left(3 \mathrm{~d}_{5 / 2}=367.9 \mathrm{eV}\right.$ and $\left.3 \mathrm{~d}_{3 / 2}=373.9 \mathrm{eV}\right)$.

This shift to lower binding energy can be related to an increase in the size of the $\mathrm{Ag}$ particles ${ }^{[50,51]}$. This is in agreement with the change seen in the crystallite size for these samples. Also, it would be expected that the linewidth would broaden as the $\mathrm{Ag}$ particles decrease in size, which was the case $\left(3 \mathrm{~d}_{5 / 2} \mathrm{FWHM} 0.75 \mathrm{eV}\right.$ to $0.63 \mathrm{eV}$ for the multilayer). The lower intensity of $\mathrm{Ag}$ for this sample is expected, as it is partially masked by the $\mathrm{TiO}_{2}$ layer, and in order to be located at the exposed surface of the sample the Ag atoms would have had to diffuse through the $\mathrm{TiO}_{2}$ layer.

High resolution Ti $2 p$ spectra (Fig. $2 b$ ) showing the $2 p_{1 / 2}$ and $2 p_{3 / 2}$ signals ( $464.7 \mathrm{eV}$, $459.0 \mathrm{eV}$ ) displayed no differences in position and width from that of a standard CVD deposited $\mathrm{TiO}_{2}$ sample.

The $\mathrm{O} 1 \mathrm{~s}$ (Fig. 2c) showed signals assigned to $\mathrm{O}$ bound to $\mathrm{Ti}^{4+}(530.2 \mathrm{ev})$ and $\mathrm{O}$ bound to $\mathrm{H}(532.8 \mathrm{ev})$ from absorbed water, on the lower trace. The upper trace for a thick layer of $\mathrm{Ag}$ (30 passes) showed only the $\mathrm{O} 1 \mathrm{~s}$ signal for absorbed water.

From this it can be confirmed that only $\mathrm{Ag}$ and $\mathrm{TiO}_{2}$ were present. There was no shift in the positions of the Ti $2 p$ and $\mathrm{O} 1$ s peaks when $\mathrm{Ag}$ was present establishing that there was no significant chemical interaction of the $\mathrm{Ag}$ with the $\mathrm{Ti}$ and $\mathrm{O}$. Quantitative calculation of the elements gave 1:1:2.2 ratio for Ag:Ti:O ie consistent with the presence of $\mathrm{Ag}$ metal and an oxide with the stoichiometry, $\mathrm{TiO}_{2.2}$.

XPS results for $\mathrm{Ag}$ over $\mathrm{TiO}_{2}$ gave very similar results to those above, confirming the presence of $\mathrm{TiO}_{2}$ and $\mathrm{Ag}$. As expected the $\mathrm{Ag}$ signals were stronger as more Ag was expected to be present at the surface layer.

For $\mathrm{Ag}$ on top and $\mathrm{Ag}$ with $\mathrm{TiCl}_{4}$ multilayer samples it can be seen that the top surface contains both $\mathrm{TiO}_{2}$ and $\mathrm{Ag}$, despite that fact that they were grown as independent layers. The XPS characteristics for the multilayer of $\mathrm{Ag}$ on $\mathrm{TiO}_{2}$ are readily explained on the basis that the Ag grows as nano-crystallites rather than as a continuous film. There are two possible explanations for the presence of $\mathrm{Ag}$ on the surface when it was originally formed as the lower layer. Either there was preferential growth of the $\mathrm{TiO}_{2}$ on the barrier glass rather than the $\mathrm{Ag}$ (inhibited on $\mathrm{Ag}$ or faster 
growth on glass) or the Ag may diffuse to the surface due to the high growth temperature required for $\mathrm{TiO}_{2}$ growth. It is notable that XPS results for $\mathrm{TiO}_{2}$ (TTIP) over $\mathrm{Ag}$ only show the upper $\mathrm{TiO}_{2}$ layer and no signal from $\mathrm{Ag}$, unlike the sample grown using $\mathrm{TiCl}_{4}$ and ethyl acetate. This is almost certainly due to the lower growth temperature, since a higher temperature would be needed to promote the diffusion of the Ag atoms. This was confirmed after the same sample was heated, at $650{ }^{\circ} \mathrm{C}$ as if for a growth experiment. Subsequent XPS analysis confirmed the presence of Ag on the surface. As expected the Ag 3d XPS peak was shifted to lower binding energy ( $\Delta=0.98 \mathrm{eV}$ ) from that of just metallic $\mathrm{Ag}$, due to the increase in Ag crystallite size $(12.8 \mathrm{~nm}$ to $17 \mathrm{~nm})$ that occurs on heating.

\subsection{UV/V is spectroscopic characteristics}

Deposition of $\mathrm{TiO}_{2}$ on top of silver showed a uv/vis absorption signal at $310 \mathrm{~nm}$ which relates to the $\mathrm{TiO}_{2}$ (See trace (a) of commercial $\mathrm{TiO}_{2}$ on glass, fig.3a). There is a signal at $357 \mathrm{~nm}$, which may be of the same origin as the shoulder seen on the $\mathrm{Ag}$ film with a long broad tail. It is interesting to note that heating the $\mathrm{Ag}$ film under $\mathrm{N}_{2}$ at $650{ }^{\circ} \mathrm{C}$ altered the signal seen. As the XRD suggested a change in crystallite size this change from $600 \mathrm{~nm}$ to $440 \mathrm{~nm}$ (and assuming that the particle size has the same directional trend) this may have been a surface plasmon related effect.

It would generally be expected that the plasmon would shift to greater energy as the particle size decreased. However, this is not the case (Ag $21 \mathrm{~nm}$ to $\mathrm{Ag}$ (annealed) 37 $\mathrm{nm})$ so other factors need to be considered. For instance a change in the spacing of the nano-particles or their shape would also lead to changes. The shift in the Ag signal for the sample of $\mathrm{TiO}_{2}$ on $\mathrm{Ag}$ again did not follow the expected trend that relates wavelength to particle size $(59 \mathrm{~nm})$. In this case as well as the factors already discussed there will also be the effect of the change of surrounding medium ${ }^{[52]}$ i.e. $\mathrm{TiO}_{2}$ rather than air, which must be taken into account sinceTiO $\mathrm{Ti}_{2}$ has a much greater dielectric constant..

The spectra from a sample prepared by growing a thin overlayer of $\mathrm{Ag}$ ( 2 passes) on $\mathrm{TiO}_{2}$ shows only a signal relating to the $\mathrm{TiO}_{2}$ and no sign of any $\mathrm{Ag}$ plasmon (fig $3 \mathrm{~b}$ ). Due to the small crystallite size $(11 \mathrm{~nm})$ and the lower $\mathrm{Ag}$ concentration th is possibly hidden by the broad, strong $\mathrm{TiO}_{2}$ absorption band. 
Spectra for a sample prepared using TTIP as a reactant in order to deposit only anatase over $\mathrm{Ag}$ (4 passes), again gave absorption bands relating to both $\mathrm{TiO}_{2}$ and a Ag plasmon. Interestingly on annealing this sample at $650{ }^{\circ} \mathrm{C}$, the surface plasmon shifted from $564 \mathrm{~nm}$ to $602 \mathrm{~nm}$. This is in line with the expected change of wavelength as the particle size increases. For the thick Ag deposition (30 passes) there is nothing to restrict the changes in the $\mathrm{Ag}$ on annealing, but in this case the $\mathrm{TiO}_{2}$ matrix may restrict some of the possible variations.

\subsection{Surface structure}

The FACVD process that we have developed leads to the growth of a nano-structured surface rather than a continuous Ag film. The density, size and spacing of the nanostructured surface will depend critically on the growth conditions chosen. This subject will be discussed in more detail in a separate paper.

In line with the crystallographic differences of the samples, the SEM images show a difference in the surface roughness and shape of the particles. The image in Fig. 4a shows growth of $\mathrm{Ag}$ (seen as bright particles) on top of $\mathrm{TiO}_{2}$. Separated $\mathrm{Ag}$ particles between $\mathrm{TiO}_{2}$ crystallites are readily observed.

The form of the $\mathrm{TiO}_{2}$ round and under the $\mathrm{Ag}$ is similar to that expected for $\mathrm{TiO}_{2}$ grown directly on a glass substrate. The example shown in figure $4 \mathrm{~b}$ for comparison is for a $\mathrm{TiO}_{2}$ layer grown using $\mathrm{TiCl}_{4}$ and ethyl acetate, with a thickness of ca. $120 \mathrm{~nm}$. There is a difference in the size of the features. That the sizing is different could be due to firstly a different layer thickness of $\mathrm{TiO}_{2}$ or secondly to the influence of the underlying Ag layer.

On deposition of the $\mathrm{TiO}_{2}$ on $\mathrm{Ag}$, distinct crystal platelets are formed (viewed in both orientations in Fig.5). These are characteristic of rutile as the sample in question was grown using $\mathrm{TiCl}_{4}$ and ethyl acetate. When compared to $\mathrm{TiO}_{2}$ grown directly on barrier glass the surface looked very different, but this is to be expected as these films are anatase only. For a better comparison, figure 5(b) shows an example of rutile grown on steel taken from other work from our laboratories ${ }^{[53]}$.

The sample (Fig. 5(c)) with an overlayer of $\mathrm{TiO}_{2}$ (TTIP grown) on $\mathrm{Ag}$ shows similar images, of the $\mathrm{TiO}_{2}$, to that of $\mathrm{TiO}_{2}$ grown direct on barrier glass. This is to be expected as both are only of anatase. In this instance the SEM images look very 
similar, although with slightly smaller features resulting from growth on the $\mathrm{Ag}$ underlayer.

Neither of the SEM images for the $\mathrm{TiO}_{2}$ overlayers on Ag showed any obvious signs of Ag nanoparticles on the surface. However, use of EDAX at a series of reducing accelerating voltages (i.e. sampling closer to the surface) clearly showed that the $\mathrm{Ag}$ signal became stronger nearer the surface, supporting our contention that at least some $\mathrm{Ag}$ is likely to be either exposed or very close to the surface of the sample

\subsection{Functional properties}

\subsubsection{Photo-activity:}

Photocatalytic activity assessment was undertaken via degradation of stearic acid under UV light (365 nm). All Ag samples gave broadly similar results irrespective of the Ag deposition thickness. For example, a thick layer gave a stearic acid decomposition rate of $0.0017 \mathrm{~cm}^{-1} \mathrm{~min}^{-1}$ while that for a thin layer was $0.0020 \mathrm{~cm}^{-}$ ${ }^{1} \mathrm{~min}^{-1}$. The multilayered films were UV active, although to varying degrees, depending on a range of factors.

3.6.1.1 Titania over Silver: $\mathrm{TiO}_{2}$ over a thick layer of $\mathrm{Ag}$ (30 passes) showed no improvement $\left(0.002 \mathrm{~cm}^{-1} \mathrm{~min}^{-1}\right)$ on single layer Ag and this in turn was much reduced compared to the reference $\mathrm{TiO}_{2}$ (single layer on barrier glass) of similar thickness

$\left(0.006,0.010 \mathrm{~cm}^{-1} \mathrm{~min}^{-1}\right.$ variation). The reduction in activity is most likely due to the presence of rutile $(58 \mathrm{wt} \%)$.

$\mathrm{TiO}_{2}$ over a thin layer of $\mathrm{Ag}$ ( 2 passes) $\left(0.015,0.010 \mathrm{~cm}^{-1} \mathrm{~min}^{-1}\right)$ was more active than $\mathrm{Ag}$ and generally higher than $\mathrm{TiO}_{2}$ alone (fig 6).

The comparison values for $\mathrm{TiO}_{2}$ on barrier glass are for pure anatase. Given that the $\mathrm{TiO}_{2}$ on $\mathrm{Ag}$ sample also contains rutile (33 wt\%), the enhancement of reactivity observed becomes all the more surprising. Containing less rutile than the previous sample may explain why the activity is greater, but the size of the improvement in activity suggests that there may be other factors in operation. For example the crystallite size may be critical for interaction. The anatase crystallites are of similar size $\left(\mathrm{TiO}_{2} \_\mathrm{Ag}(2)\right.$ at $38 \mathrm{~nm}$ and $\mathrm{TiO}_{2} \_\mathrm{Ag}(30)$ at $33 \mathrm{~nm}$, but the rutile crystallites are smaller for the sample with the thin underlayer of $\mathrm{Ag}\left(\mathrm{TiO}_{2} \mathrm{Ag}(2) 30 \mathrm{~nm}\right.$, $\left.\mathrm{TiO}_{2} \mathrm{Ag}(30) 5 \mathrm{lnm}\right)$. 
Growth of $\mathrm{TiO}_{2}$ using TTIP over Ag (4 passes) gave an activity of $0.0024 \mathrm{~cm}^{-1} \mathrm{~min}^{-1}$ for the combined layer, which is similar to that of just the Ag, but less than that for a single layer of $\mathrm{TiO}_{2}\left(0.006 \mathrm{~cm}^{-1} \mathrm{~min}^{-1}\right)$ of similar thickn ess .

The conditions of growth of $\mathrm{TiO}_{2}$ have been shown to alter some of the physical properties of the underlying $\mathrm{Ag}$ (e.g. crystallite size) and so this in turn may effect the activity of the multilayer, along with the rutile/anatase ratio. Usually where a significant amount of rutile is formed the activity of the film is reduced as compared to a film composed solely of anatase. However, in this case it is possible that the presence of a small amount may be beneficial, since the slightly smaller bandgap of rutile $(3.0 \mathrm{eV})$ overlapping with that of anatase $(3.2 \mathrm{eV})$ may result in a wider absorbance range. Rutile has a faster $\mathrm{e} / \mathrm{h}$ recombination rate than anatase so generally less efficient for photoactivity ${ }^{[54]}$. However, according to Sclafani ${ }^{\left[49,{ }_{55}\right]}$ addition of $\mathrm{Ag}$ will improve the activity for rutile, but not for anatase. They suggest that for the case of rutile the $\mathrm{Ag}$ captures the free electrons, hence enhancing electron-hole pair dissociation and improving the photoactivity. However for anatase although this will occur the Ag ions then preferentially attract holes and become recombination centres. Another factor influencing the photoactivity could be the amount of $\mathrm{Ag}$ on the surface. This has been discussed in various papers describing sol-gel $\mathrm{Ag} / \mathrm{TiO} \mathrm{f}_{2}$ films for which the amount of $\mathrm{Ag}$ is reported as critical ${ }^{[23,56,57]}$ i.e. the photoactivity decreases above an optimum $\mathrm{Ag}$ level. In our case it suggests that the $\mathrm{TiO}_{2}-\mathrm{Ag}(2)$ film having the lower amount of $\mathrm{Ag}$ on the surface is closer to the optimum value. The lack of improvement in combined activity for the TTIP grown multilayer sample again suggests the optimum amount of Ag is not on the surface, this being effected by differences in the growth experiment, which in turn change the rate at which $\mathrm{Ag}$ diffuses though the $\mathrm{TiO}_{2}$ film. The differences in the growth experiment include use of an alternative precursor (and hence different crystal structures) and a lower growth temperature. It is also noteworthy that the sol-gel film studies in question use different methods to test the activity so cannot be directly compared as identical samples will have different activity to different pollutants. We have recently highlighted the general problems associated with variable activity testing in our work on the possible role of N-doping ${ }^{[55]}$. This variability of activity, in the case of $\mathrm{Ag}$ in $\mathrm{TiO}_{2}$ (sol-gel), was discussed by Tran et al ${ }^{[52]}$ who concluded that Ag would only enhance activity (over $\mathrm{TiO}_{2}$ ) for pollutants predominantly oxidised by holes and not those that require hydroxyl radicals for mineralisation. Interestingly however, although Tran does not 
test stearic acid, a similar acid (isobutyric acid) tested by them does not show an increased activity with Ag.

3.6.1.2 Silver over Titania: A thin layer of Ag (2 passes) was deposited on laboratory thermally grown $\mathrm{TiO}_{2}$. $\mathrm{Ag}(2)$ on $\mathrm{TiO}_{2}$ activity $\left(0.0082 \mathrm{~cm}^{-1} \mathrm{~min}^{-1}\right)$ (Sample A in fig. 7) is referenced against $\mathrm{TiO}_{2}$ chosen from the thickest area of the substrate before the $\mathrm{Ag}$ was grown. This reference should indicate the maximum activity available from anywhere on the CVD coated plate, (average $0.007 \mathrm{~cm}^{-1} \mathrm{~min}^{-1}$ ). To illustrate the effect of thickness, a second point chosen from a thinner area, gives a lower activity of $0.006 \mathrm{~cm}^{-1} \mathrm{~min}^{-1}$ (fig 7, Sample B).

To eliminate the complication s associated with variable laboratory $\mathrm{TiO}_{2}$ thickness, $\mathrm{Ag}$ (2) was deposited on a (uniform) commercially available $\mathrm{CVD} \mathrm{TiO}_{2}$ coated glass giving photo-activity of $0.0054 \mathrm{~cm}^{-1} \mathrm{~min}^{-1}$ (over $60 \mathrm{mins}$ ) against the commercial $\mathrm{TiO}_{2}$ coating of av erage $0.003 \mathrm{~cm}^{-1} \mathrm{~min}^{-1}$. (fig 8)

Whilst both these sets of results indicate intriguing $\mathrm{Ag}$ enhancement of $\mathrm{TiO}_{2}$ activity, particularly when $\mathrm{TiCl}_{4}$ and ethyl acetate are used as reactants - the relationship appears complex with factors such as film $\left(\mathrm{TiO}_{2}\right.$ and $\left.\mathrm{Ag}\right)$ thickness, surface topography likely to be important. Further studies of this effect are proposed for the future.

\subsubsection{Biocidal activity}

The combined thermal and FACVD grown multi-layer films were investigated for biocidal activity using E. coli as test organism. Plain glass was used as a control. Comparisons were made between FACVD Ag layers alone, photoactive $\mathrm{TiO}_{2}$ films and FACVD Ag overcoated with $\mathrm{TiO}_{2}$. All the Ag films used were about $60 \mathrm{~nm}$ thick (4 passes), while the comparison $\mathrm{TiO}_{2}$ reference samples were approximately $80 \mathrm{~nm}$ thick.

The biocidal activity was measured by the technique outlined in section 2. Example results are shown in fig. 9a for a $\mathrm{TiO}_{2}$ layer only, fig $9 \mathrm{~b}$ for $\mathrm{Ag}$ on glass and $\mathrm{TiO}_{2}$ over $\mathrm{Ag}$ (fig 9c).

It can be seen that the thermally grown $\mathrm{TiO}_{2}$ film is biocidally active, but the timescale for $100 \%$ kill (6 log reduction) was between 180 and $240 \mathrm{~min}$. This was slower than that obtained for the Ag and the combined films. All the Ag films tested were highly bacteriocidal, and most gave effectively $100 \%$ kill in under the standard 
minimum measurement time of 40 mins. Although the rate of killing was somewhat slower on $\mathrm{TiO}_{2}$ over $\mathrm{Ag}$, this has to be considered against the significant enhancement of durability.

Once again we must highlight the fact that drawing comparisons to other data available in the literature is complicated by the variation in procedures.

Sokmen et al ${ }^{[29]}$ used $\mathrm{TiO}_{2}$ loaded with $1 \% \mathrm{Ag}$ but in suspension and got $100 \%$ kill in 15 min probably due to the presence of silver ions. On $\mathrm{TiO}_{2}$ alone, Amezaga Madrid ${ }^{[9]}$ only got a $70 \%$ reduction after 40 min whereas Sunada et al ${ }^{[7]}$ saw a $6 \log$ kill after 90 min with similar bacteria loadings to our own, but kill time were longer with larger doses.

Kikuchi et al ${ }^{[4]}$ reported a $4 \log$ reduction in 1 h. Kuhn et al ${ }^{[5]}$ reported a $6 \log$ reduction of E. coli on P25 coated plexiglass in $1 \mathrm{~h}$. In conclusion, the bioactivity of the thin films grown in this work, are the most active we have seen reported, based on our 40 min minimum test time. However, we have recently modified our test procedure and early results indicate kill speeds are actually less than 5 min (for $6 \log$ kill), which would indicate a further substantial improvement in bioactivity. Further work to confirm this result, and the technique reproducibility, is underway.

To test the durability of the film photoactivity, a number of $\mathrm{TiO}_{2}$ samples were repeatedly cycled through the biocidal test procedure followed by the stearic acid test, with samples being cleaned each time (Sonicated in methanol and then chloroform for 30 mins). The stearic acid results indicated no measurable reduction in maintained photoactivity, within the accuracy of the test, over 3 test cycles. (fig 10). It is noteworthy that the films are also mechanically durable. Titania over silver is hard and scratch resistant and will have the longest term stability. However, silver over titania also appears durable. Whilst some of the silver can be abraded away, the surface remain bio-active. This is presumably due to silver being trapped within the titania surface structure.

To demonstrate the ability of the films to regenerate under the influence of UV irradiation (under identical to stearic acid test conditions), $\mathrm{TiO}_{2}$ coatings were again coated with bacteria and UV irradiated. At the end of the test the films were visibly contaminated with dead bacteria residues. The samples, as seen, were tested for photoactivity with the stearic acid test (fig 11a) showing significant deactivation. The 
experiment was then repeated, with the additional initial step of UV irradiation (18 hrs) of the films and the samples again tested for stearic acid photoactivity activity. Fig $11 \mathrm{~b}$ illustrates an example set of results showing that whilst the (dead) bacteria contaminated $\mathrm{TiO}_{2}$ film is strongly deactivated ( $\left.\boldsymbol{\bullet}\right)$, UV regeneration $(\boldsymbol{\Delta})$ recovered a significant percentage of the original activity. The effect is considered to be due to the self-clean ing high photoactivity of the $\mathrm{TiO}_{2}$.

\section{Summary}

We have developed a new CVD process for the deposition of Ag from aqueous solutions. This has then been used in conjunction with conventional thermal CVD to produce layered $\mathrm{Ag}$ and $\mathrm{TiO}_{2}$ structures.

All grown films were polycrystalline, consisting of cubic $\mathrm{Ag}$ and $\mathrm{TiO}_{2}$. The $\mathrm{TiO}_{2}$ is stoichiometric anatase when the bottom layer and a mixture of anatase and rutile when grown on top of the $\mathrm{Ag}$ when grown using $\mathrm{TiCl}_{4}$ and ethyl acetate. Using TTIP the $\mathrm{TiO}_{2}$ forms as anatase whether grown under or over the Ag. The crystallite size of the Ag substantially increases when annealed during the high temperature growth of the $\mathrm{TiO}_{2}$ layer. XPS confirms that there is no chemical interaction between the $\mathrm{Ag}$ and the $\mathrm{TiO}_{2}$. One of the interesting features of this work is that although the $\mathrm{Ag}$ and $\mathrm{TiO}_{2}$ layers were grown sequentially the overall result shows that the surface consists of both $\mathrm{Ag}$ and $\mathrm{TiO}_{2}$, for $\mathrm{TiO}_{2}$ samples grown with $\mathrm{TiCl}_{4}$ and ethyl acetate.

All the samples have some UV photoactivity, which is of differing values depending on the exact arrangement of the layers. The addition of Ag layers gives comparable or improved photoactivity of the multilayers, particularly in the case of $\mathrm{Ag}$ on $\mathrm{TiO}_{2}$, over that of single layer of $\mathrm{Ag}$ or $\mathrm{TiO}_{2}$ of comparable thickness.

The bioactivity results show a high degree of activity for both $\mathrm{Ag}$ and $\mathrm{Ag} / \mathrm{TiO}$ films and interestingly the most active results are from $\mathrm{Ag}$ under $\mathrm{TiO}_{2}$. Indeed, the results are the most active, for thin films, reported to date. The proposed mechanism for this activity is one that is strongly influenced by the thickness of the $\mathrm{TiO}_{2}(80 \mathrm{~nm})$. Our data suggest that this should be sufficiently thick so as to develop critical level crystallinity, but thin enough to allow silver to diffuse through (and into) the $\mathrm{TiO}_{2}$ film as it grows. This is supported by the reported XPS results. 
It should be noted that the UV levels employed in this work are of a similar intensity to that found in full sun light.

We can speculate that the nano-structure of Ag deposited by FACVD may be crucial in determining bio-activity. $\mathrm{Ag}$ grown on glass or $\mathrm{Ag}$ overcoated with $\mathrm{TiO}_{2}$, both benefit from the high structure control capability of the FACVD approach. When deposited onto $\mathrm{TiO}_{2}$, the structure flexibility will be, at least, partially pre-defined by this underlayer.

Silver molecules can be oxidised at the silver /titania interface, we have designed the multi-layer system to incorporate diffusion based replenishment capability, thus giving the potential for extended activity. It is interesting to note that atomic absorption measurements of the bacteria solutions above the films showed concentrations below 1ppm (Atomic Abs. detection limit).

The combination of $\mathrm{Ag}$ by FACVD and $\mathrm{TiO}_{2}$, by CVD, offers two unique advantages: Firstly, the $\mathrm{CVD} \mathrm{TiO}_{2}$ coating imparts a major enhancement to durability. Initial tests show retained activity along with chemical and abrasion resistance compatible with many potential applications.

Secondly, the $\mathrm{Ag} / \mathrm{TiO}_{2}$ film has "dual activity" and "dual functionality". The film dual biocidal activity comes from both Ag toxicity to bacteria, and also from the photo-activity of the $\mathrm{TiO}_{2}$. The dual functionality comes from combining $\mathrm{Ag}$ derived bio-activity along with the self-regeneration capability of the photo-active $\mathrm{TiO}_{2}$.

One of the major limitations of conventional biocidal surface technology is that once the surface is contaminated above a certain level, the underlying bacteriocidal action is blocked. Such contamination is very common. It can derive from sources such as food derived residues, or from the previously killed bacteria, which otherwise would be a platform for new bacterial growth. Combining a biocidal surface with a selfcleaning capability, gives the potential for not only high activity, but selfregeneration.

In addition, it is noteworthy that the combined $\mathrm{Ag} / \mathrm{TiO}_{2}$ films are thin and as such impart only moderate changes to visual appearance.

This new combined and flexible process, the resultant multi-functionality, and the associated transparency and durability, offers new opportunities for enhanced application in the increasing number of areas where bio-active surface functionality is sought. 
5. Acknowledgements: This work was partially financed by the EC through GRD12001-40791, PHOTOCOAT project. LB thanks Corus Plc for financial support.

\section{References}

[1] A.Mills, S. Le Hunte, J.Photochem Photo Biol A, 1997, 108, 1.

[2] T. Matsunaga, R. Tomada, T. Nakajima, H. Wake, FEMS Microbiol. Lett. 1985, 29, 211.

[3] P-C, Maness, S. Smolinski, D.M. Blake, Z. Huang, E.J. Wolfrum, W.A. Jacoby, Appl Env Microbiol. 1999, 65, 4094.

[4] Y. Kikuchi, K. Sunada, T. Iyoda, K. Hashimoto, A. Fujishima, J Photochem Photobiol. A, 1997, 106, 51.

[5] K.P. Kuhn, I.F. Chaberny, K. Massholder, M. Stickler, V.W. Benz, H-G. Sonntag, L. Erdinger, Chemosphere, 2003, 53, 71 .

[6] J.C. Yu, W. Ho, J. Lin, H. Yip, P.K. Wong, Environ Sci Technol. 2003, 37, 296.

[7] K. Sunada, Y. Kikuchi, K. Hashimoto, A. Fujishima, 1998, Environ. Sci.

Technol. 32, 726.

[8] K. Sunada, T. Watanabe, K. Hashimoto, Environ Sci Technol. 2003, 37, 4785.

[9] P. Amézaga-Madrid, G.V. Nevárez-Moorillón, E. Orrantia-Borunda, M. Miki-

Yoshid a, FEMS Microbiol Lett. 2002, 211,183.

[10] Hip pocrates, "On Ulcers," 400 B.C.E.; translated by Franc is Adams, (http://clas sics.mit.edu/Browse/browse-Hippocrates.html)

[11] A.D. Russell, W.B. Hugo, "Antimicrobial activity and action of silver" in Progress in Medicinal Chemistry, Vol. 31 (Eds: G.P. Ellis, D.K. Luscombe), St. Louis, Elsevier Science, St. Louis, Mo.1994, 351.

[12] S. Silver, FEMS Microbiol Rev. 2003, 27, 341.

[13] E. Verne, S. Di Nunzio, M. Bosetti, P. Appendino, C. Vitale Brovarone, G. Maina, M. Cannas, Biomat. 2005, 26, 5111.

[14] a)R.O. Fernández, R.A. Pizarro, Photochem. Photobiol. 1996, 64, 334.

b) K.S. Rogers, Biochem Biophys Acta. 1972, 263, 309.

[15] S. Liau, D. Read, W. Pugh, J. Furr, A. Russell, Letters in Applied Microbiology, 1997, 25, 279.

[16] J.L. Clement, P.S. Jarrett, Metal-Based Drugs, 1994, 1, 467.

[17] R.H. Jen sen, N. Davidson, Biopolymers, 1966, 4, 17.

[18] P.D. Bragg, D.J. Rainnie, Can J. Microbiol. 1973, $20,883$.

[19] F.F-R. Fan, A.J. Bard, Journal of Physical Chemistry B. 2002, 106, 279.

[20] S. Thomas, P. McCubbin, Journal of Wound Care, 2003, 12, 101.

[21] K. Dunn, V. Edwards-Jones, Burns, 2004, 30, S1.

[22] C.He, Y.Yu, X.Hu, A.Larbot, Appl.Surf.Sci. 2002, 200, 239.

[23]A. Dobosz, A. Sobczynski, Water Res. 2003, 37, 1489.

[24] E.Stathatos, T.Petrova, P. Lianos, Langmuir, 2001, 17, 5025.

[25] P.D.Cozzoli, E. Fanizza, R. Comparelli, M.L. Curri, A. Agostiano, D. Laub, J.Phys.Chem.B, 2004, 108, 9623.

[26] T. Hirakawa, P.V. Kamat, J.Am.Chem.Soc. 2005, 127, 3928. 
[27] J.M. Herrmann, H. Tahiri, Y. Ait-Ichou, G. Lassaletta, A.R. Gonzalez-Elipe, A. Fernandez, Appl.Catal.B, 1997, 13, 219.

[28]S. Kato, Y. Hirano, M. Iwata, T. Sano, K. Takeuchi, S. Matsuzawa, Applied Catalysis B-Environmental, 2005, 57, 109.

[29] M. Sökmen, F. Candan, Z. Sümer, J Photochem ,Photobiol A, 2001, 143, 241.

[30] M. Machida, K. Norimoto, T. Kimura, J Am Ceram Soc. 2005, 88, 95.

[31] Y. Li, P. Leung, L. Yao, Q.W. Song, E. Newton, J Hosp Infect. 2006, 62, 58.

[32] A.Grodzickla, I. Lakomska, K. Piszcze, I. Smzmanka, E. Szlyk, Co-ordination chemistry reviews, 2005, 249, 2232.

[33] M.Abourida, H.Guillon, C. Jemenez, J.M. Decams, F. Weiss, O. Valet, P.

Doppelt, Electrochemical Society Pro. 2003, 2003-08, 938.

[34] D.A. Edwards, M. Harker, M. Mahon, K. Molloy, Inorganica Chemica Acta, 2002, 328, 134.

[35]R.A. Spurr, H. Myers, Anal.Chem. 1957, 29, 760 .

[36]Yates, M.G. Nolan, D.W. Sheel, M.E.Pemble, Electrochemical Society

Proceedings, 2005, 2005-09, 783

[37] P.Evans, M.E.Pemble, D.W.Sheel, in preparation

[38] P.K. Song, M. Vamagishi, H. Odaka, Y. Shigesato, Jpn.J.Appl.Phys. 2003, 42. L1529.

[39] B.D. Cullity, Elements of XRD, Addison-Wesley, 1978.

[40] R.van de Krol. A. Goossens, J.Vac.Sci.Technol.A, 2003, 21, 76.

[41] T. Ung, L.M. Liz-Marzan, P. Mulvaney, Colloids and surfaces A, 2002, 202, 119

[42] S.Link, M.A. El-sayed, J.Phys ChemB, 1999,103, 8410

[43] Handbook of XPS, (Ed.J.Chastain, R.C. King), Physical Electronic Inc. 1995

[44] K.Luo, T.P. St.Clair, X.Lai, D.W. Goodman, J.Phys.Chem.B,2000,104, 3050

[45] W.Huang, Z. Jiang, F. Dong, X. Bao, Surf.Sci. 2002, 514, 420.

[46] P. Mulvan ey, Langmuir, 1996,12, 788.

[47] P.Evans, PhD thes is, University of Salford, 2005.

[48] C.Leo, H. Choi, C. Lee, H. Kim, Surf.Coating Technol. 2003, 173, 192.

[49]A.Sclafani, J.M. Herrmann, J.Photochem.biolA, 1998, 113, 181.

[50]I.M.Arabatzis, T.Stergiopoulos, M.C. Bernard, D.Labou, S.G. Neophytides,

P.Falaras, Appl.Cat.B, 2003, 42, 187.

[51] M.W. Xu, S.J. Bao, X.G. Zhang, Mat.Lett. 2005, 59, 2194.

[52] H.Tran, K.Chiang, J.Scott, R.Amal, Photochem.Photobiol.Sci.2005, 4, 565

[53] M.G. Nolan, D.W. Sheel, M.E. Pemble, Electrochemical Society Pro. 2003, 2003-08, 41.

[54] M.J. Davis, G. Benito, D.W. Sheel, M.E. Pemble, Chemical Vapor Deposition, 2004,10, 29 .

[55] H.M.Yates, M.G. Nolan, D.W. Sheel, M.E. Pemble, J.Photochem.PhotoBiol.A, 2006, 179, 213.

[56] Y. Paz, Z. Luo, L. Rabenberg, A. Heller, J.Mater.Res.1995,10, 2842.

[57] P. Sawunyama, L. Jiang, K. Hash imoto, J.Phys.Chem.B, 1997, 101, 11000.

[58] A. Mills, G. Hill, S. Bhopal, I.P. Parkin, S.A. O'Neill, J.Photochem.Photobiol.A, 2003, 160,185 . 


\section{Fig ures}

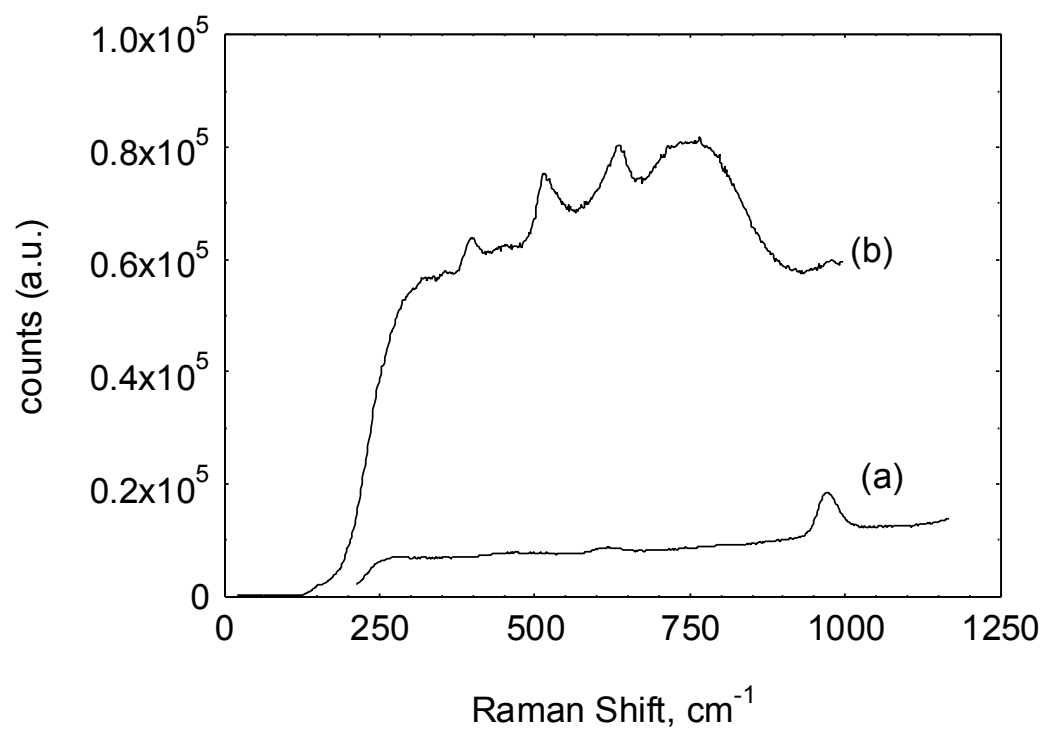

fig 1: Raman spectra for silver and $\mathrm{TiO}_{2}$ over silver films
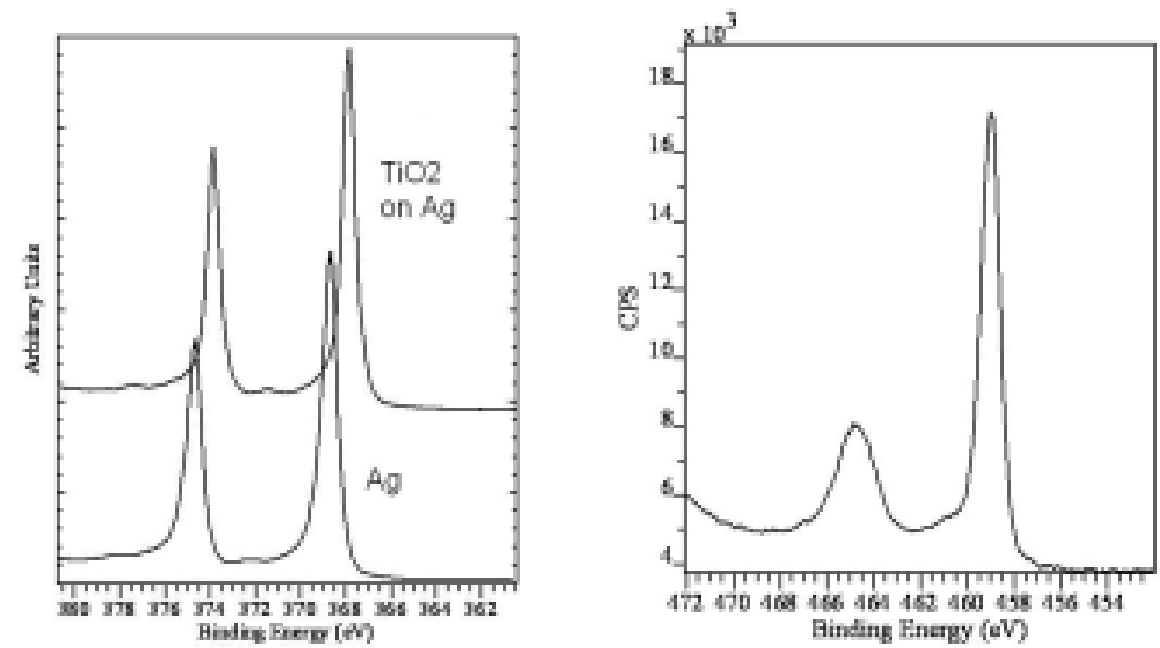

Fig. 2 - XPS high resolution scan of $\mathrm{TiO}_{2}$ over $\mathrm{Ag}$ (30) (a) $\mathrm{Ag} 3 \mathrm{~d}$ (Inc luding sample $\mathrm{Ag}(30$ ), (b) $\mathrm{Ti} 2 \mathrm{p}$ 


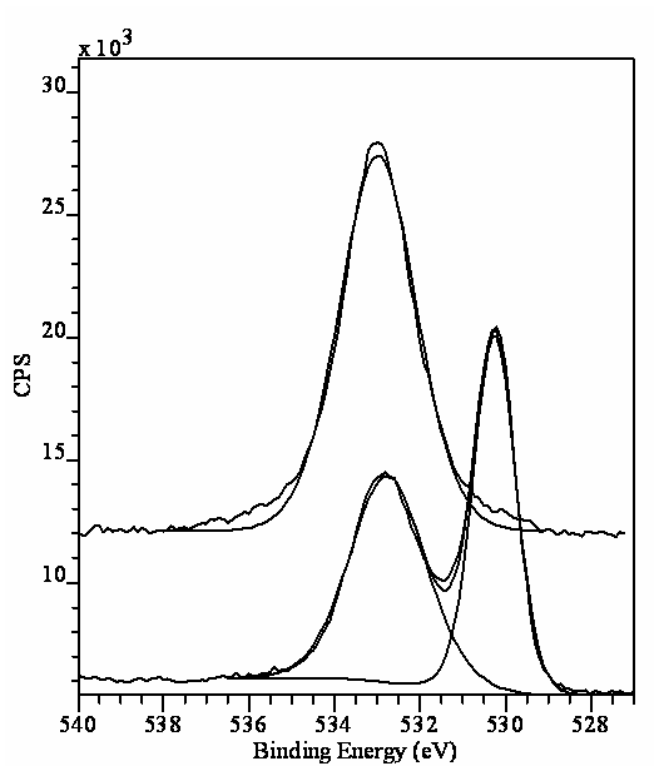

Fig. 2(c) - XPS high resolution scan for O 1s

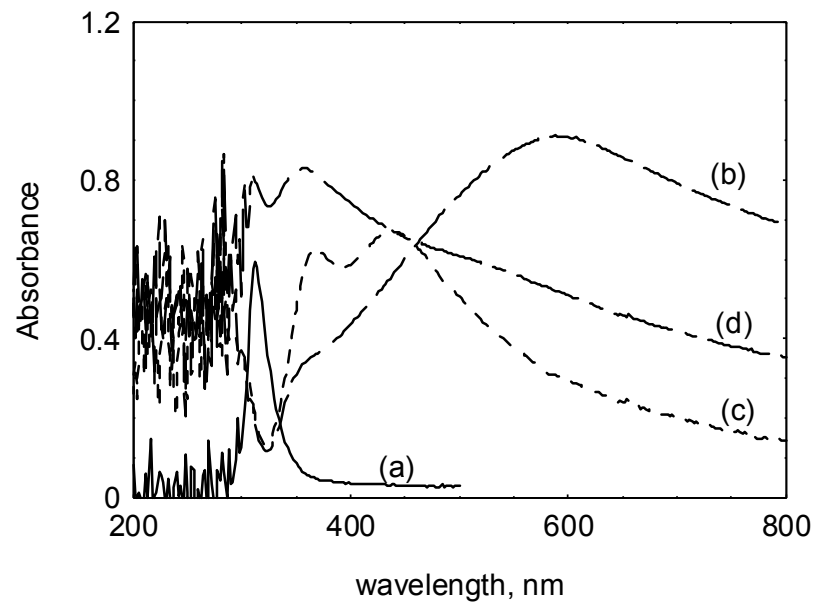

fig. 3 (a): UV/Vis spectra of (a) commercial $\mathrm{T}_{2}$ on glass, (b) Thick layer of $\mathrm{Ag}$ (30 passes), (c) Annealed $\mathrm{Ag}(30)$, (d) $\mathrm{TiO}_{2}$ on $\mathrm{Ag}(30)$ 


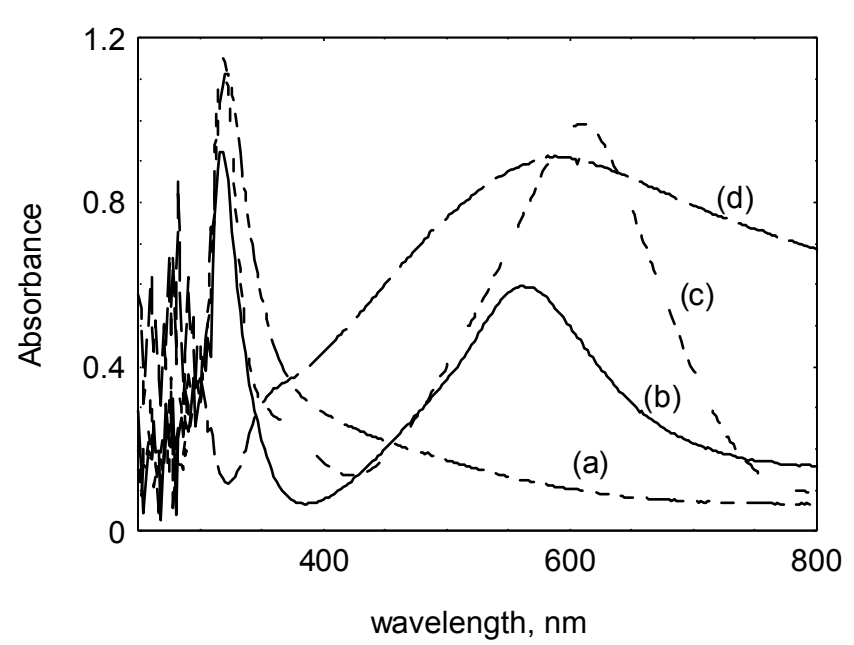

fig. 3(b): UV/Vis spectra of (a) Thin layer of $\mathrm{Ag}$ (2 pass es ) over $\mathrm{TiO}_{2}$ (b) $\mathrm{TiO}_{2}$ (TTIP) over $\mathrm{Ag}$ (4 passes), (c) Annealed $\mathrm{TiO}_{2}$ (TTIP) over Ag (4 passes), (d) Thick layer of Ag (30 passes)
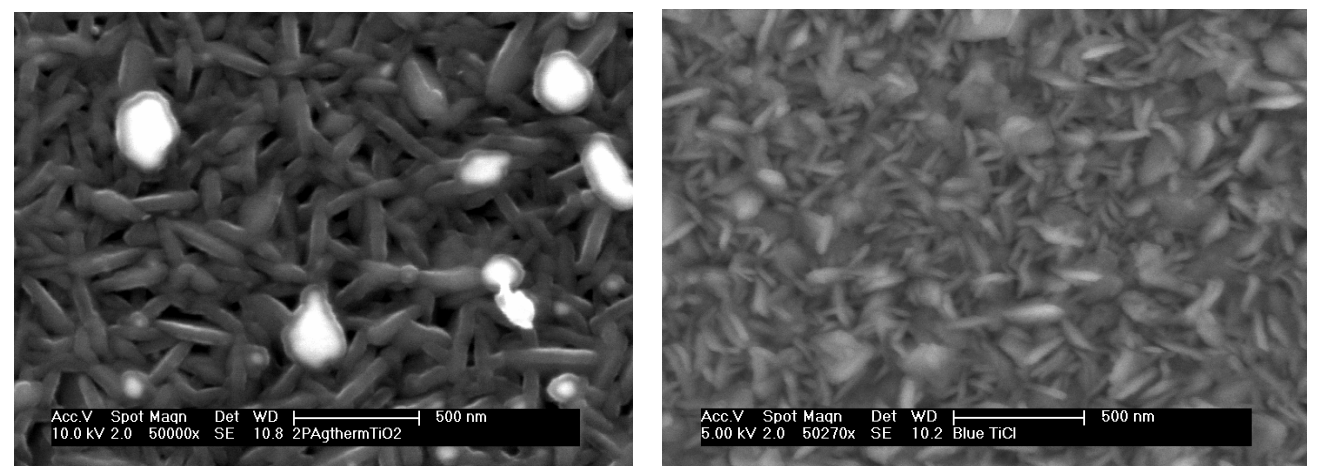

Fig 4 Growth of (a)Ag (2) on top of $\mathrm{TiO}_{2}$, (b) $\mathrm{TiO}_{2}$ on barrier glass
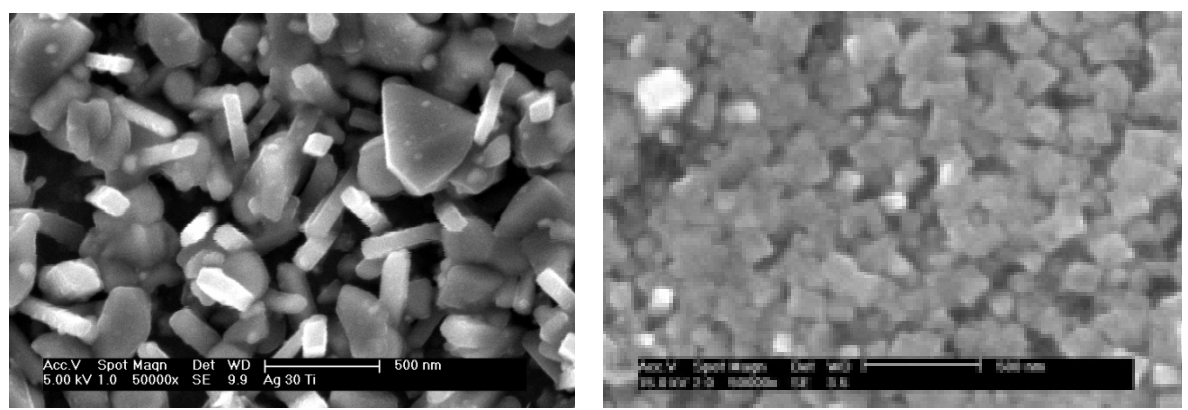

Fig. 5, (a) $\mathrm{TiO}_{2}$ on $\mathrm{Ag}(30)$, showing mainly rutile platelets. (b) rutile on steel 


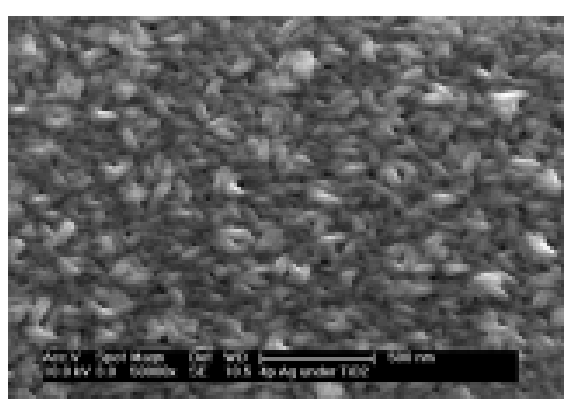

Fig. 5(c) SEM image of $\mathrm{TiO}_{2}$ (TTIP) over Ag (4 passes)

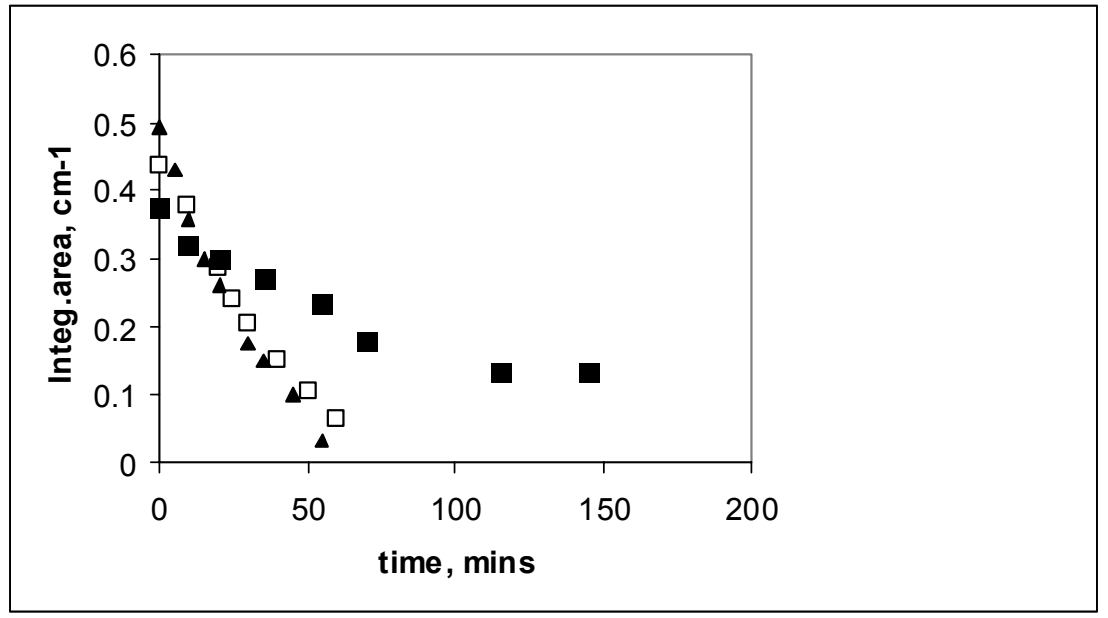

fig 6: Photoactivity (stearic acid), $\boldsymbol{\triangle A g}(2), \square \mathrm{TiO}_{2}$ on $\mathrm{Ag}(2), \boldsymbol{\Delta} \mathrm{TiO}_{2}$ on $\mathrm{Ag}$ repeat

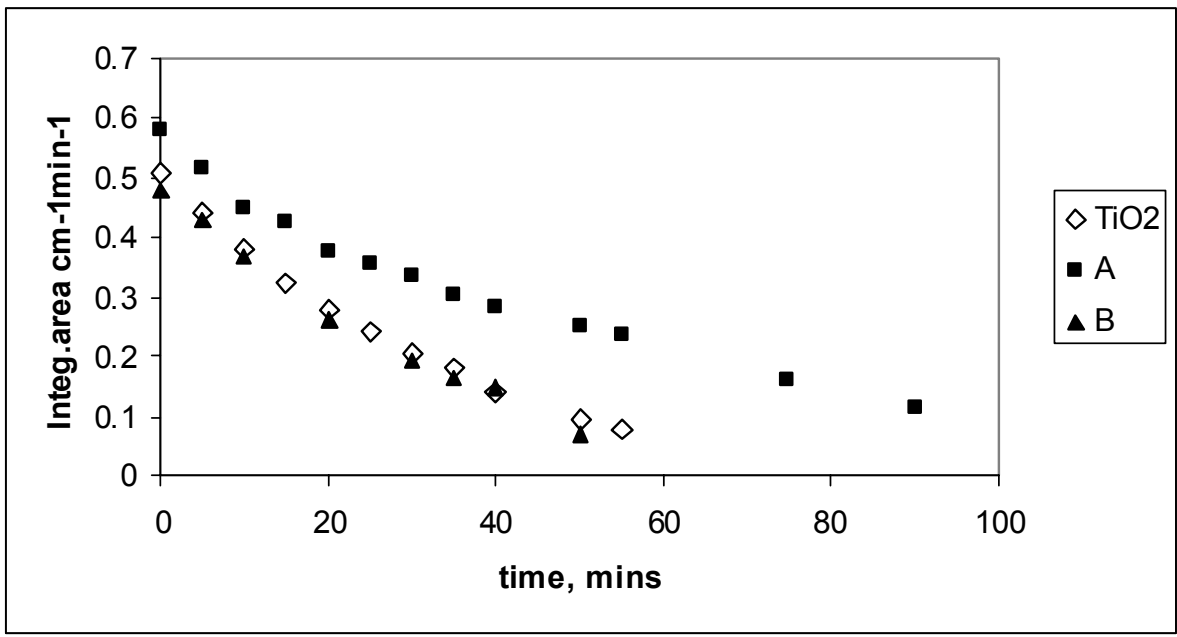

fig 7: Examples of photoactivity (stearic acid) $\mathrm{Ag}$ over $\mathrm{TiO}_{2}$ and reference $\mathrm{TiO}_{2}$. 


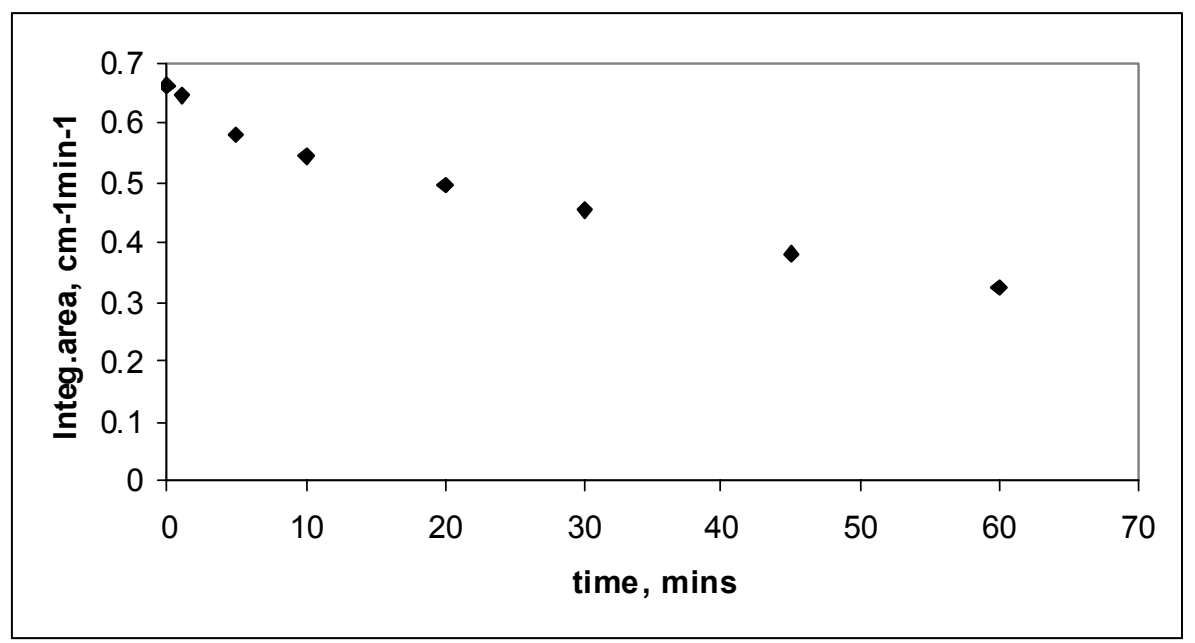

fig 8: Photoactivity of silver on commerc ial $\mathrm{TiO}_{2}$ coating

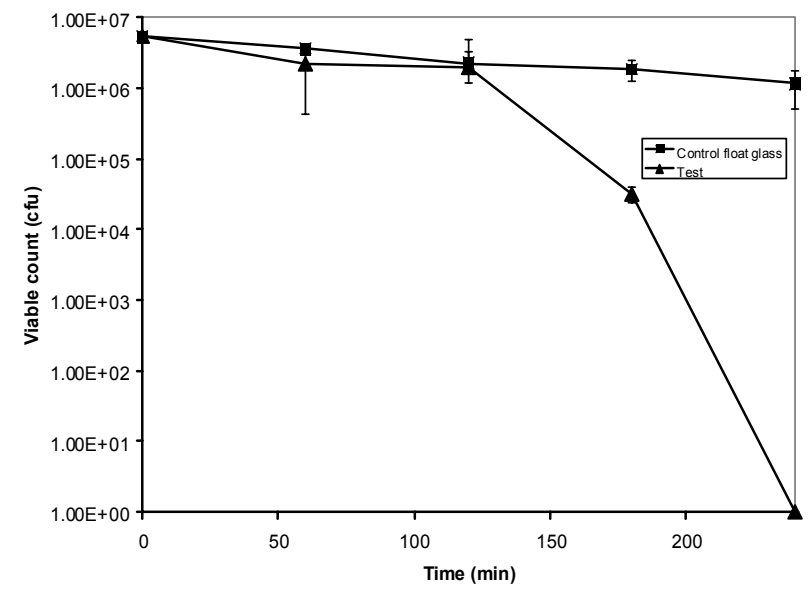

fig 9 (a) $\mathrm{Lab}$ thermal $\mathrm{CVD} \mathrm{TiO}_{2}$ film on glass

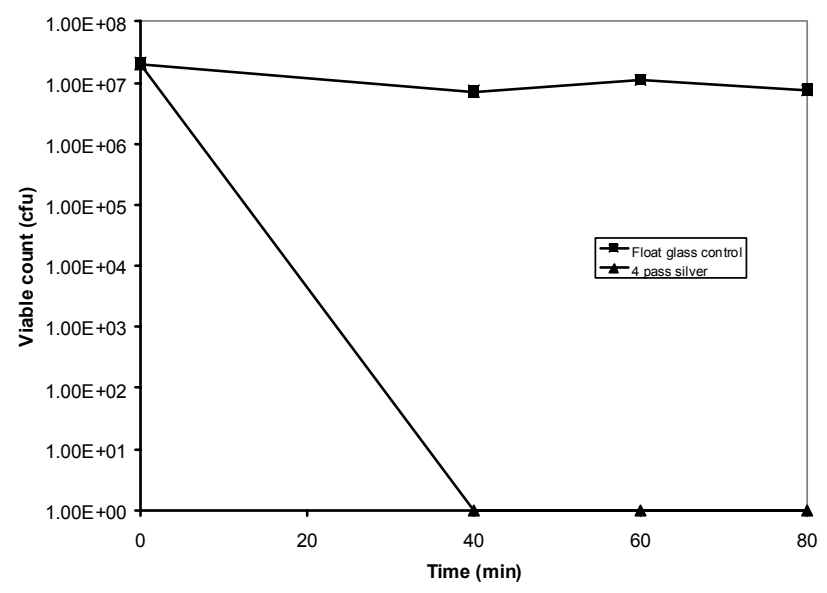


fig 9(b) Ag layer on glass (note: minimum test time 40mins)

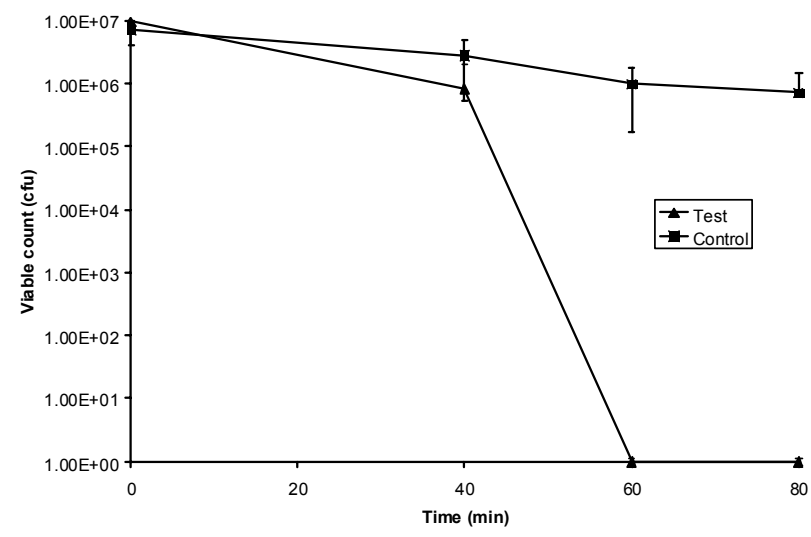

fig 9 (c) $\mathrm{TiO}_{2}$ layer on top of $\mathrm{Ag}$ on glass

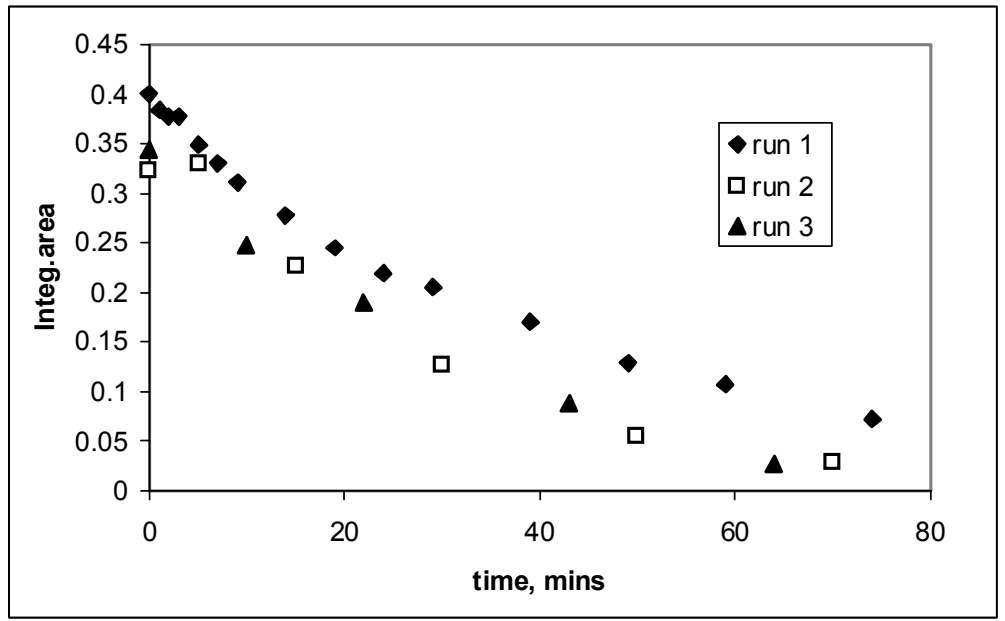

fig: 10 . An example sample showing the retention of photoac tivity after bio ac tivity testing. 


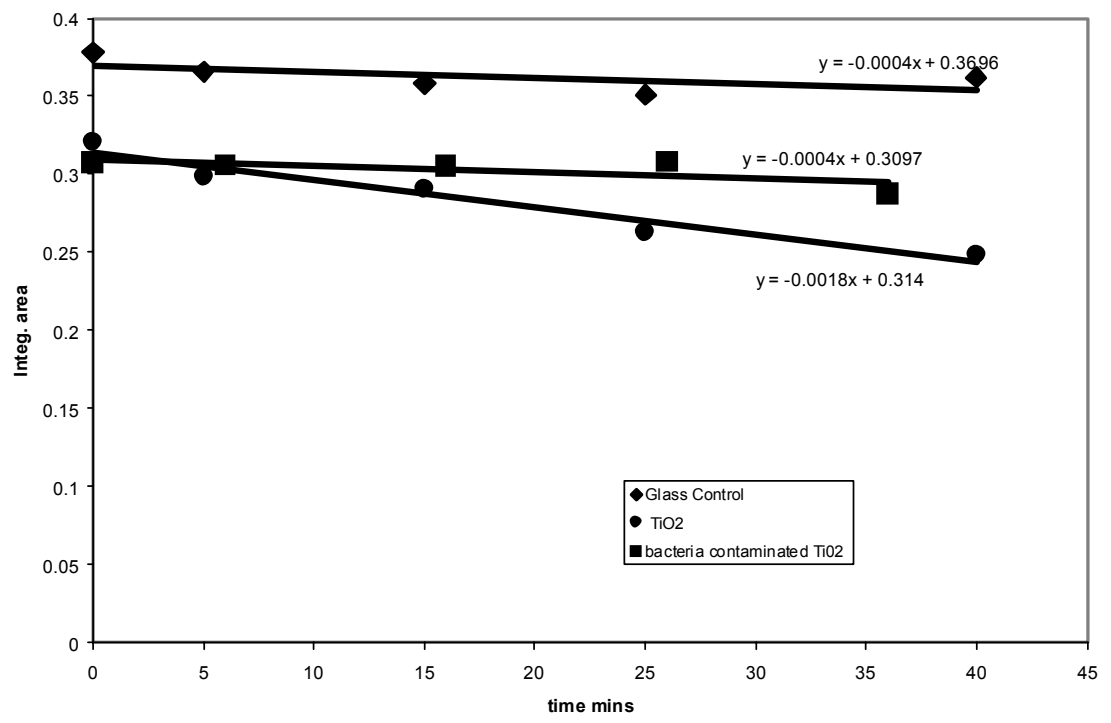

Fig 11(a). Photoactivity after bio-contamination

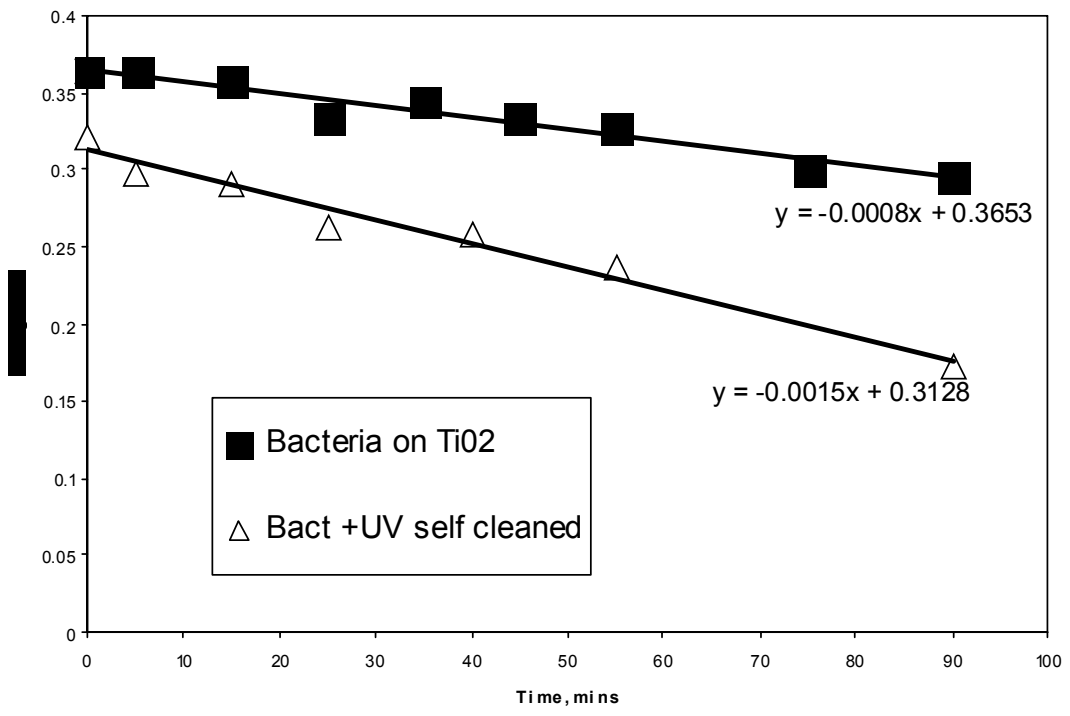

Fig 11(b). Photoactivity after UV "self regeneration" 